\title{
Occupational Performance in Children Aged 6 to 13 Years with Cancer
}

\author{
Soraya Gharebaghy ${ }^{1}$, Sedigheh Sadat Mirbagheri², Khadijeh Khazaeli* \\ 1. Department of Occupational Therapy, School of Rehabilitation Sciences, Iran University of Medical Sciences, Tehran, \\ Iran \\ 2. Department of Orthotics and Prosthetics, University of social welfare and rehabilitation sciences, Tehran, Iran \\ 3. Department of Occupational Therapy, School of rehabilitation sciences, Isfahan University of Medical Sciences, \\ Esfahan, Iran
}

\begin{tabular}{c} 
Article Info \\
\hline Received: $2017 / 03 / 28$ \\
Accepted: $2017 / 06 / 05$ \\
Published Online: $2017 / 10 / 29$ \\
DOI: \\
10.30699/fdisj.01.1.49 \\
How to Cite This Article \\
Gharebaghy S, Mirbagheri S \\
S, Khazaeli K. Occupation- \\
al Performance in Cancer \\
Children Aged 6 to 13 Years. \\
Func Disabil J. 2018; 1 (1) \\
:49-57
\end{tabular}

Use your device to scan and read the article online

\section{ABSTRACT}

Background and Objectives: Cancer survival rate increased during the last 3 decades, following medical advances and improvement of therapeutic protocols to treat children with cancer. Contribution to childhood activities is essential to the growth and development of children, regardless of their ability and disability. However, there is no information about the problems and requirements of childhood activities in children with cancer undergoing cancer therapy. The purpose of this study is to provide information about the occupational performance needed in children with cancer.

Methods: A cross-sectional study was conducted to evaluate high priority problems in occupational performance in children with cancer. Occupational performance needs and priorities were determined by a semi-constructed interview using the Canadian occupational performance measure (COPM). The obtained data were encoded and statistically analyzed.

Results: Based on the problems noted by the children with cancer, a total of 141 problems were selected in the occupational performance areas out of which 37 codes were extracted. Results of the current study indicated that based on COPM, among 3 main occupational performance areas, the most problematic area belonged to self-care (49.64\%), then productivity and leisure time (26.95\% and $23.40 \%$, respectively).

Conclusion: Results of previous as well as the current studies indicated that children with cancer, due to the complications of the disease and side-effects of the therapies, face some functional problems in their daily life activities, which emphasizes the need for occupational therapy practices in order to improve the patients' QoL.

Keywords: Cancer, Occupational performance areas, Occupational performance satisfaction, Occupational performance priorities in daily life

Corresponding Information: Khadijeh Khazaeli, Department of Occupational Therapy, School of rehabilitation sciences, Isfahan University of Medical Sciences, Esfahan, Iran Email: kh.khazaeli@yahoo.com

Copyright (C) 2018, Function and Disability Journal. This is an open-access article distributed under the terms of the Creative Commons Attribution-noncommercial 4.0 International License which permits copy and redistribute the material just in noncommercial usages, provided the original work is properly cited.

\section{Introduction}

Successful participation in activities of daily living, in home and school, is essential for the growth and development of children. Based on the International Classification of Functioning, Disability and Health (ICF), damage to body function and structure results in limited activities (Organization, 2001). Activity lim- itations in children result in participation restriction in playing, school activities, etc. (Rodger et al., 2003). There are numerous internal and external factors influencing the performance of a child. Occupational performance results in acquiring the adequacy in a wide range of activities and successful participation in the activities that are socially appropriate and de- 
velopmentally fit for the child, and provides a meaningful life for him/her (Crawford, Wilson, Dewey, 2001; Laliberte-Rudman, 2002).

Childhood cancer is a rather rare event (Moore, 2005) associated with excessive fear and anxiety (Rencken, 2011). Due to the medical advances and improvement of therapeutic protocols to treat children with cancer within the last 3 decades, most such patients survive and get back to almost normal life (Moore, 2005; Hartman et al., 2013; Kamble). The most common cancers among children are brain tumors, abdominal tumors, leukemia, and lymphoma that are curable by early and appropriate diagnosis (Rencken, 2011). Hence, the focus of pediatric oncology and other members of the multidisciplinary team shift toward the identification and management of the disease as well as the side effects and impacts of cancer therapies on the quality of life (QoL) in children with cancer. The treatments used for the children are associated with many side effects and cause problems to various body organs and systems; for example, visual deficits, hearing loss, deficits in learning, memory and attention deficits, executive function disorders, and poor eye-hand coordination (Hudson et al., 2003). Children with cancer also experience neurocognitive and neuropsychological effects such as poor visual constructional ability, decreased IQ, distractibility, impulsivity and poor mathematics and reading skills and poor school performance. The side effects of cancer treatment can result in physical, cognitive or affective changes that can impact occupational wellbeing.

In addition, children with cancer experience functional complications that are very similar to the ones experienced by children with sensory integration disorder (SID) (Rencken, 2011; Hudson et al., 2003). Such children experience problems in academic performances, concentration, self-regulation, compliance with the environment, and learning abilities (Eilertsen, Rannestad, Indredavik, Vik, 2011).

Due to decreased cancer-related mortality, there has been a move towards improved QoL (Miralles, Ramón, Valero, 2016). Occupational therapy in practice affects the QoL (Berg, 2009); participation in valuable occupations allows the person to experience recognition of his/her identity; participation in such performances indicates the value of a person and gives meaning to his/her life (Liddle, McKenna, 2000). The QoL is the key outcome of occupational therapy (OT) interventions (Liddle, 2000; Strong, 1987).

Participation in childhood occupations is essential to children's growth and development, regardless of their ability and disability. Childhood roles develop the sense of personal independence in children; the child should become productive and participate in play or leisure time activities. During the participation in daily activities, children learn new skills. Engaging in new experiences and activities allows the children to positively develop their self-esteem. Inability to participate in daily activities may result in social isolation, which can negatively impact children (Rodger, Ziviani, 2006).

Most of the times, medical complications or disabilities affecting social and developmental status of children (particularly the activities of daily life, participation and self-perception) are neglected. Independence in daily life activities is important to the general health and is the basic element in any definition of health. Such activities constitute the tasks that one should be regularly performing in order to participate in occupational and social roles. Performing such activities is among the first achievements in childhood, which significantly assists the promotion of independence and socialization in children. Daily life activities are of great importance to the caregivers and parents, since incapability in such practices reduces the amount of support provided for the children. When a child is born with disability or becomes disabled later, the expectations of parents for his/her independence in daily life affairs change (Desai, 2008).

Although childhood participation is essential to the growth and development of children, regardless of their ability or disability, no information was available about the problems and requirements of occupational performance in children with cancer undergoing cancer therapies. The purpose of this current study was to increase our information of occupational performance difficulties and priorities of children with cancer. 


\section{Material and Methods}

The cross sectional study was conducted to evaluate occupational performance needs and priorities in children with cancer. For this purpose, a total of 29 elementary school children with cancer admitted to Pediatric Oncology Department of Bésaat Hospital, Hamadan, Iran, in 2015 were selected. The inclusion criteria were; being diagnosed with cancer, an age range between 7 to 13 years, possessing verbal and communicative abilities, and willingness of the child and the parents to participate in the study. The children with underlying diseases such as cerebral palsy, autism, etc., and severe visual, auditory, and intellectual deficits were excluded. Based on the inclusion and exclusion criteria, 16 male and 13 female students were invited to the study. After providing enough information about the study, its objectives, and methods, the subjects and their parents signed the informed consent forms. Then, demographic information including age, gender, grade, duration of the disease, and the type of cancer was recorded for each subject. To determine occupational performance problems and functional priorities in daily life, a semi-structured interview based on the Canadian occupational performance measure (COPM) was used. The subjects were asked to report their daily life needs in different occupational areas. Then, the researcher categorized the occupational performance needs reported by the children according to their importance.

COPM is a client-centered measuring tool, which measures the self-perception of the patient toward his/ her occupational performance using a semi-structured interview; it can be performed at any time. COPM evaluates different aspects of occupational performance and is also applicable to a wide range of age groups and disabilities. This scale can be used to identify therapeutic goals in the areas of self-care, productivity, and leisure time. Based on COPM, occupational performance includes self-care, productivity, and leisure time; it is influenced by the environment, social role of the person, and his level of development. Occupational performance is introduced by certain references and contains 2 aspects of performance and satisfaction (Dehghan, Dalvand, Pourshahbaz, 2015; Law, 1998).

COPM is conducted in the platform of a semi-constructed interview and takes 20-30 minutes. COPM is performed by occupational therapists. It has a 4-step process: 1 . determining the occupational performance items; 2. estimating and scoring the importance; 3 . recording; 4. re-evaluating (Law, 1998).

\section{Results}

A total of 29 children with cancer were finally interviewed based on COPM. During the interview, the final code list of occupational performance problems contained over 141 items. The functions were encoded and out of which 68 items belonged to self-care area, 38 to productivity, and 33 to leisure time. Then, the authors primarily categorized the reported problems and introduced 37 codes based on the COPM scale. Based on the introduced codes, the problems were placed in one of the self-care, productivity, and leisure time areas. It is noteworthy that only the first 5 priorities reported by the children based on COPM were analyzed. The participants' demographic data are shown in Table 1. Based on the data in Table 1, most of the participants were male (55.2\%), within the age range of 7-12 years, and were the primary school students $(65.35 \%)$.

According to Table 3, out of 141 problems noted by the study participants, the highest frequency belonged to self-care area (49.64\%), then productivity $(26.95 \%)$, and leisure time $(23.40 \%)$.

Of $49.64 \%$ of the problems placed in self-care area $(\mathrm{n}=70), 44$ cases belonged to personal care subscale that had the highest frequency among other subscales of this area. Functional mobility had the second place in this area with $14.2 \%$ frequency.

Productivity had the second highest frequency with $26.95 \%$ after self-care. Regarding its subscales, school games got the highest frequency $(n=33,23.40 \%)$.

Leisure time had the third place, and the highest frequency belonged to the subscale of socialization $(12.05 \%)$. 
Table 1. Absolute and Relative Frequency Distribution of Demographic Variables

\begin{tabular}{ccccccccc} 
Variable & \multicolumn{2}{c}{ Gender } & \multicolumn{2}{c}{ Educational Level } & \multicolumn{2}{c}{ Age (yr) } & Total \\
Group & Male & Female & Preschool & Primary School & 6 & $7-13$ & 25 \\
Number & 16 & 13 & 4 & 25 & 4 & 25 & 29 \\
Percentage & 55.2 & 44.8 & 13.8 & 86.2 & 13.8 & 86.2 & 100 \\
\hline
\end{tabular}

Table 2. Frequency Distribution Based on the Type of Cancer

\begin{tabular}{ccccccccccc}
\multirow{2}{*}{ Group } & \multicolumn{4}{c}{ Type of Cancer } & \multicolumn{3}{c}{ Treatment } \\
& CML & Histiocytosis & All & Sarcoma & OOB & AML & Yes & No & Total \\
Number & 1 & 1 & 22 & 2 & 1 & 2 & 24 & 82.8 & 100 \\
\hline Percentage & 3.4 & 3.4 & 79.9 & 6.9 & 3.4 & 6.9 & 5 & 17.2 & 100 \\
\hline
\end{tabular}

Table 3. Frequency Distribution of Problems of Children with Cancer

\begin{tabular}{|c|c|c|c|}
\hline \multirow{5}{*}{ Self-care } & & Frequency & Frequency Percentage \\
\hline & Personal care & 44 & 31.20 \\
\hline & Functional mobility & 20 & 14.2 \\
\hline & Social management & 6 & 4.25 \\
\hline & Total & 70 & 49.64 \\
\hline \multirow{4}{*}{ Productivity } & $\begin{array}{c}\text { Working with/without } \\
\text { wages }\end{array}$ & 1 & 0.7 \\
\hline & Home management & 4 & 17.73 \\
\hline & School games & 33 & 23.40 \\
\hline & Total & 38 & 26.95 \\
\hline \multirow[t]{5}{*}{ Leisure time } & Entertainments & 2 & 19.2 \\
\hline & Active entertainments & 14 & 9.9 \\
\hline & Socialization & 17 & 12.05 \\
\hline & Total & 33 & 23.40 \\
\hline & & 141 & 100 \\
\hline
\end{tabular}

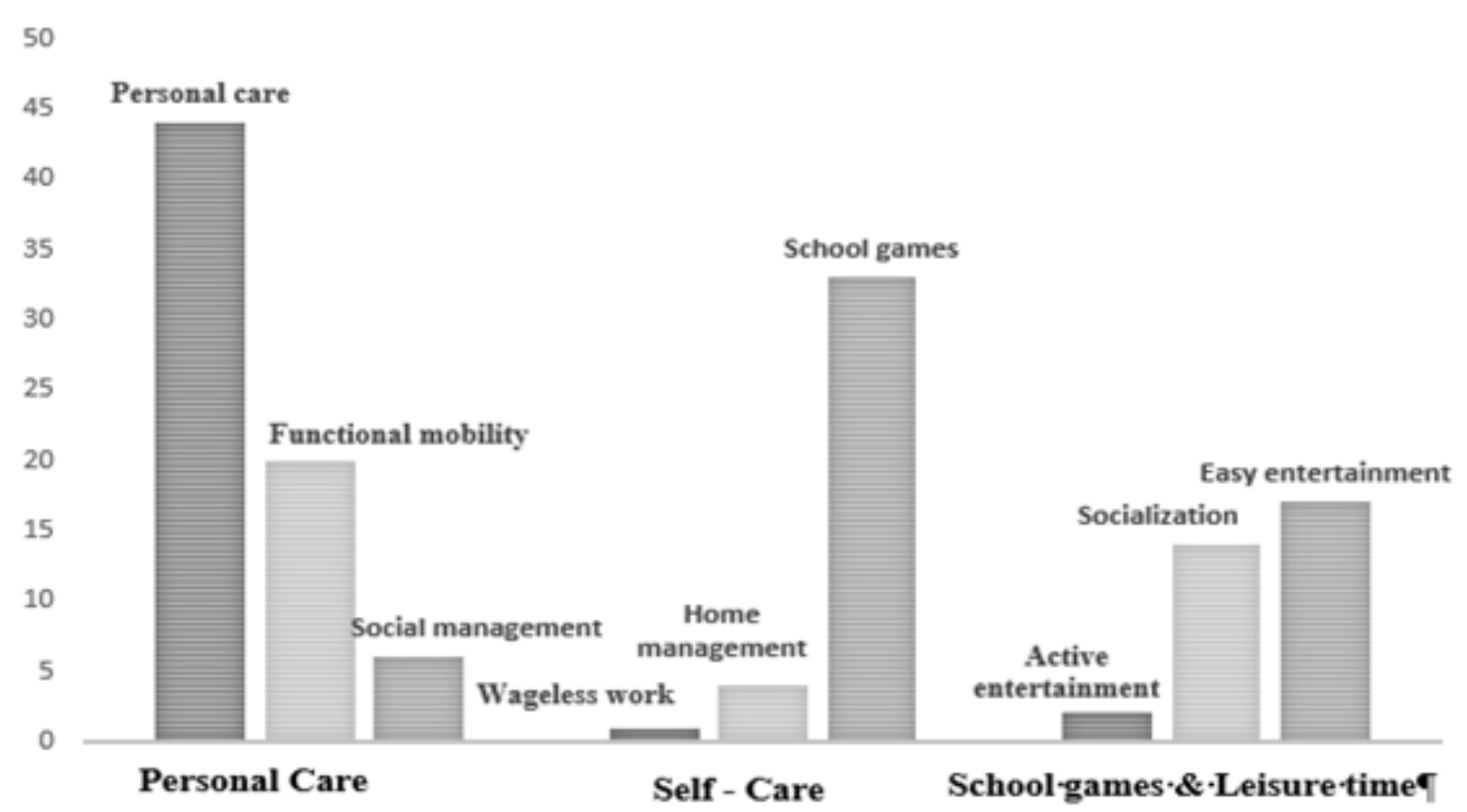

Fig 1. Frequency Distribution of Problems Noted by Children with Cancer in 3 Performance Areas 


\section{Discussion}

Occupational therapists believe that the occupational balance is essential to health and welfare; occupational balance is determined based on the time the person spends on self-care, productivity, and leisure time. Children with cancer usually experience imbalance during hospital stay or due to the side effects of therapies. In fact, the families of children with cancer do the daily personal affairs of such children due to their special conditions (Strong, 1987). Following medical advances and improvement of medications for cancer, life expectancy increased in children with such diseases. Therefore, paying more attention to the secondary problems as well as side effects of cancer therapies in such patients is of great importance. Based on the conducted studies, cancer therapies have numerous side effects and cause problems to different body organs and systems in the affected children such as visual deficits, reduced hearing acuity, learning, memory, and attention deficits, executive function disorders, and poor eye-hand coordination (Rencken, 2011).

The cancer complications, side effects of its treatment, and long-time hospital stay may cause cognitive, emotional, and physical changes, which affect the welfare of children with cancer (Strong, 1987). The central nervous system (CNS) of children with cancer is affected by the disease and its complications and causes learning deficits, attention-deficit/ hyperactivity disorder, and occupational as well as educational deficits. Neurological deficits of children with cancer include learning deficits, poor attention and memory, executive function deficit, poor eyehand coordination, paresthesia, drop foot, and ataxia, spasticity, as well as seizure and dementia with severe manifestations (Moore, 2005). In addition, children with cancer experience performance complications that are very similar to the ones experienced by children with SID. Such children usually have problems in academic performance, concentration, self-regulation, compliance with the environment, and learning abilities (Rencken, 2011).

Children with cancer experiencing the side effects of primary cancer therapies, or hospitalized for a long time do not feel well to participate in learning and playing activities and may miss the chance of acquiring problem solving, social interaction, and physical skills. Long-time hospital stay is associated with delayed growth and development, eating problems, social behavior complications, and problems with the level of activity and attention. Most of such children stay in bed; they do not have enough strength and get tired soon, and prefer to participate in activities that need the least movement and environment discovery (Keene, 2010).

Children with cancer experience disintegration in childhood activities; they face problems in self-care activities (getting dressed, bathing, eating, etc.), productivity (doing school, kindergarten, and routine tasks), and playing and leisure time (QoL and social interactions). Occupational therapists can help resolve such problems, and finally provide interventions in order to provide welfare for children with cancer and empower them to participate in the activities.

Based on the results of the current study, most of the problems noted by the children belonged to self-care area; hence, the performances attributed to personal care, getting dressed, and eating were considered as the subscales of this area. Most of the children with cancer were incapable of playing at school, doing personal care, had problems with functional mobility and socialization.

Based on the results of the study by Marline et al., (1998) on the long-term effect of cancer on the gross motor function of children with cancer, poor gross motor function was reported in children with cancer, compared with their healthy peers (Wright, Halton, Martin, Barr, 1998). Owing to the fact that the perceived motor proficiency is an important factor in children's selfesteem, the motor function of children with cancer is reduced after chemotherapy (Hartman, Van den Bos Stijnen, Pieters, 2008). Since cognitive and motor-sensory skills are the basis for many daily life activities, deficits in each of them can affect the occupational performance of children; the results of the current study were also in agreement with these findings and 
owing to the importance of personal care in personal independence, most of the problems $(32.20 \%)$ reported by the current study subjects were in the self-care area, followed by productivity (26.95\%), and leisure time $(23.40 \%)$.

Based on results of the study by Mohammadi et al, (2017) cancer diagnosis and treatment can restrict participation in activities of daily living (Mohammadi, 2017). Priorities determined in the self-care area were personal care, motor function, and social management, which respectively constituted $31.20 \%$, $14.2 \%$, and $4.25 \%$ of the total reported problems, and the reason, can be attributed to the fact that children need mobility to manage their daily life activities. Due to the significant role of personal care in childhood independence, it seems that personal care can be one of the main aspects of occupational challenges in children with cancer. In addition, children with cancer reported fatigue caused by long-time activities, which need higher rates of performance tolerance, as the main reason for unwillingness to participate in the mentioned activity areas, and since most of the daily life activities are conducted to fulfill personal care needs and require higher mental and performance tolerance, they can be considered as one of the main reasons for self-care area problems in children with cancer.

Based on the results of the current study, most of the self-care area problems reported by the study subjects belonged to school games $(23.40 \%)$. Owing to the age range of the study, and the fact that the main occupation of children in this age range is playing, the attention of children with cancer to their incapability in the effective implementation of self-care area occupations resulted in higher scores in this area.

Based on the results of the current study, $12.05 \%$ of children with cancer had problems in socialization activities and it seems that owing to the important role of recreation, entertainment, and socialization and its impact on the acceptance of people by the community as well as promotion of self-esteem, this area had the highest priority.

\section{Conclusion}

Results of the current study indicated 3 areas in occupational performance which include self-care, productivity, and leisure time, respectively in terms of priority. In addition, based on COPM, priorities were the skills in playing, bathing, going to parties, getting dressed, doing homework, and eating, respectively. Results of the current study showed that children with cancer, and due to the complication of the disease and the side effects of cancer therapies and drugs, experience challenges in their daily occupational performances, which indicates the need for rehabilitation interventions, particularly occupational therapy, to reduce current challenges and improve QoL in such patients.

\section{Limitations}

One of the main limitations of the current study was the small sample size, since children with cancer did not show willingness to cooperate with the study due to the type of their disease, reduced tolerance, and side effects of chemotherapy. Also, temporary hospitalization of such children and transferring them to the outpatient department was another limitation of the study. It seems that owing to the support provided for children with cancer, they accepted their disabilities in the reported occupational areas and did not consider them as problems; where one of these areas was social activity.

\section{Acknowledgments}

The authors acknowledge their gratitude to the children and their families for cooperating and taking part in the study. Also, they wish to thank the authorities of Bésaat Hospital of Hamadan, particularly the officials of Oncology Department, Dr. Esfahani, and Misses Zahra Saadat and Mahdis Arab, and the other colleagues who helped with the project.

\section{Conflict of Interest}

Authors declared no conflict of interest. 


\section{References}

Berg C, Neufeld P, Harvey J, Downes A, Hayashi RJ. Late effects of childhood cancer, participation, and quality of life of ado-lescents. OTJR: Occupation, Participation and Health. 2009;29(3):116-24.

Crawford SG, Wilson BN, Dewey D. Identifying developmental coordination disorder: consistency between tests. Physical \& oc-cupational therapy in pediatrics. 2001;20(2-3):29-50.

Dehghan L, Dalvand H, Pourshahbaz A. Translation of Canadian Occupational Performance Measure and testing Persian ver-sion validity and reliability among Iranian mothers of children with cerebral palsy. Journal of Modern Rehabilitation. 2015;9(4):25-31.

Desai A. Comparison of functional independence, community participation and occupational self-perception of children with attention deficit hyperactivity disorder and children without attention deficit hyperactivity disorder: ProQuest; 2008.

Eilertsen MEB, Rannestad T, Indredavik MS, Vik T. Psychosocial health in children and adolescents surviving cancer. Scandi-navian journal of caring sciences. 2011;25(4):725-34

Hartman A, Hop W, Takken T, Pieters R, van den Heuvel-Eibrink M. Motor performance and functional exercise capacity in survivors of pediatric acute lymphoblastic leukemia. Pediatric blood \& cancer. 2013;60(3):494-9.

Hartman A, Van den Bos C, Stijnen T, Pieters R. Decrease in peripheral muscle strength and ankle dorsiflexion as long-term side effects of treatment for childhood cancer. Pediatric blood \& cancer. 2008;50(4):833-7.

Hudson MM, Mertens AC, Yasui Y, Hobbie W, Chen H, Gurney JG, et al. Health status of adult long-term survivors of child-hood cancer: a report from the Childhood Cancer Survivor Study. Jama. 2003;290(12):1583-92.

Kamble R, Goswami S, Saigal J, Sarin R, Jalali R. PROSPECTIVE NEURO-COGNITIVE ASSESSMENT (USING LOTCA) AND QUALITY OF LIFE (QOL) AND ACTIVITIES OF DAILY LIVING (ADL) IN CHILDREN WITH BRAIN TUMOUR TREATED WITH SURGERY AND LOCALIZED HIGH-PRECI-
SION RADIOTHERAPY. Indian Journal of Occupational Therapy.35(3).

Keene N. Childhood leukemia: A guide for families, friends \& caregivers: Childhood Cancer Guides; 2010.

Laliberte-Rudman D. Linking occupation and identity: Lessons learned through qualitative exploration. Journal of Occupation-al Science. 2002;9(1):12-9.

Law MC, Baptiste S, Carswell A, McColl MA, Polatajko H, Pollock N. Canadian occupational performance measure: Canadian Association of Occupational Therapists Ottawa ON; 1998.

Liddle J, McKenna K. Quality of life: An overview of issues for use in occupational therapy outcome measurement. Australian Occupational Therapy Journal. 2000;47(2):77-85.

Miralles PM, Ramón NC, Valero SA. Adolescents with cancer and occupational deprivation in hospital settings: A qualitative study. Hong Kong Journal of Occupational Therapy. 2016;27:26-34.

Mohammadi A, Mehraban AH, Damavandi SA, Zarei MA, Amini M. Participation in Daily Life Activities among Children with Cancer. Middle East Journal of Cancer. 2017;8(4):213-22.

Moore BD. Neurocognitive outcomes in survivors of childhood cancer. Journal of Pediatric Psychology. 2005;30(1):51-63.

Organization WH. International Classification of Functioning, Disability and Health: ICF: World Health Organization; 2001.

Rencken G. Prevalence of sensory integrative dysfunction in the childhood cancer population. 2011.

Rodger S, Ziviani J, Watter P, Ozanne A, Woodyatt G, Springfield E. Motor and functional skills of children with developmental coordination disorder: A pilot investigation of measurement issues. Human movement science. $2003 ; 22(4): 461-78$.

Rodger S, Ziviani J. Childrens roles, occupations and participations in contemporary society. Occupational Therapy with Chil-dren. 2006:3-21.

Strong J. Occupational therapy and cancer rehabili- 
tation. The British Journal of Occupational Therapy. 1987;50(1):4-6.

Wright MJ, Halton JM, Martin RF, Barr RD. Long-term gross motor performance following treatment for acute lymphoblastic leukemia. Medical and pediatric oncology. 1998;31(2):86-90. 


\section{مقالة يزوهشى \\ مشكلات عملكرد كارى در كودكان مبتلا به سرطان 9 تا سا سال}

\section{ثريا قرباغى'، صديقه سادات ميرباقرى ‘، خديجه خزائلى"}

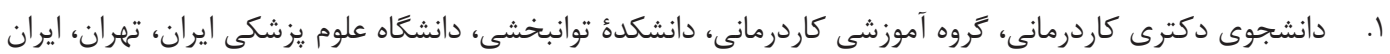

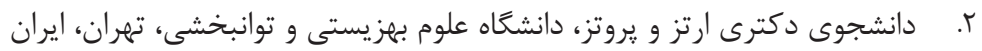

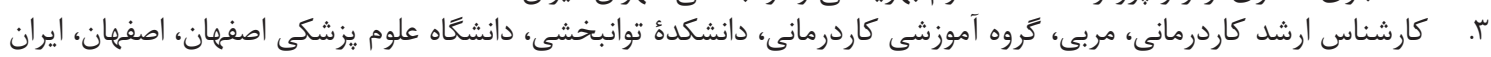

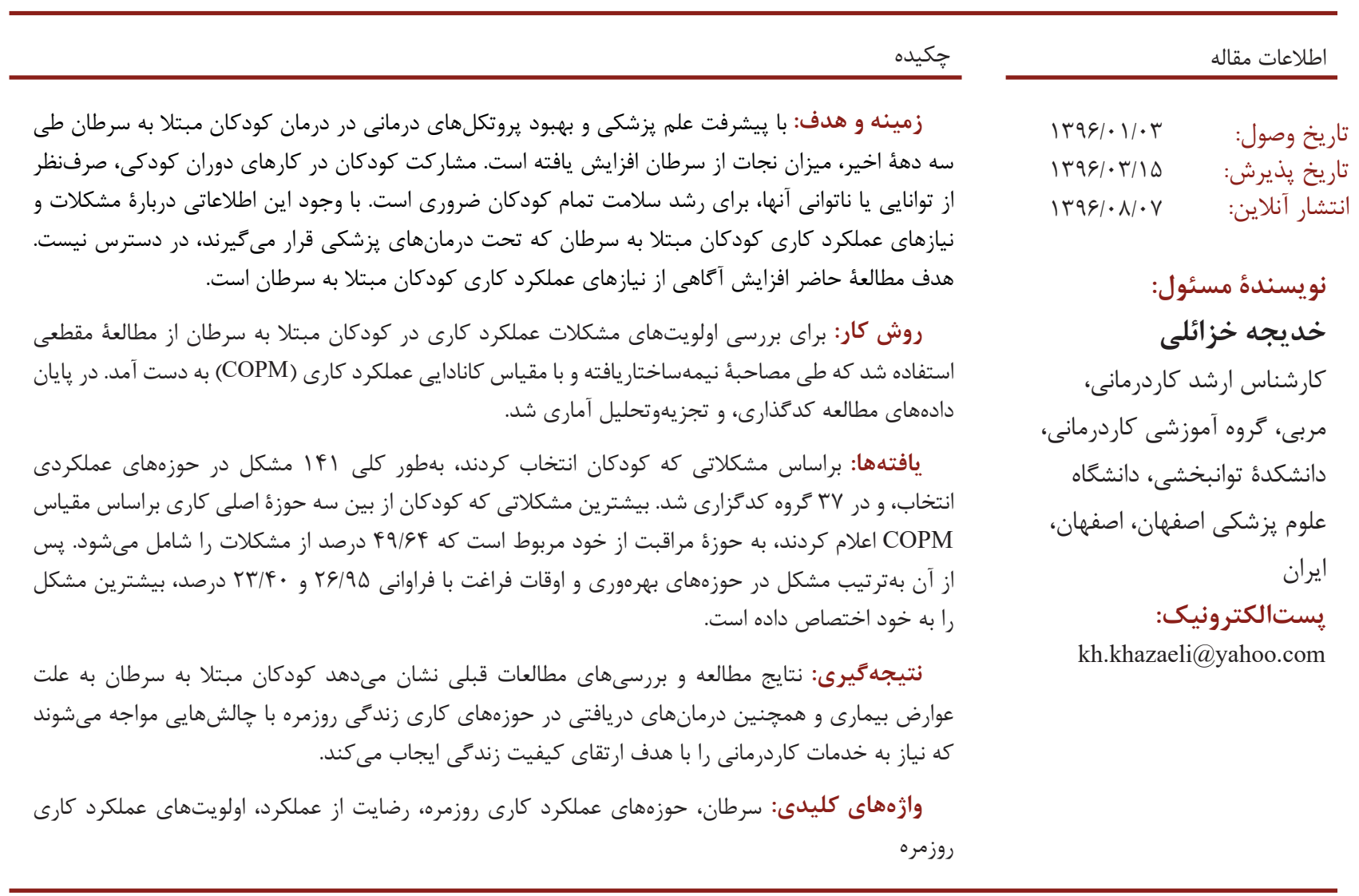

